Brazilian Journal

of Chemical

ISSN 0104-6632

Engineering

Printed in Brazil

www.abeq.org.br/bjche

\title{
Zymomonas mobilis IMMOBILIZED ON LOOFA SPONGE AND SUGARCANE BAGASSE FOR LEVAN AND ETHANOL PRODUCTION USING REPEATED BATCH FERMENTATION
}

\author{
V. A. Q. Santos ${ }^{1 *}$ and C. H. G. Cruz ${ }^{2}$ \\ ${ }^{1}$ Engineering and Food Technology Department, São Paulo State University (UNESP) \\ Cristóvão Colombo Street, 2265, Jardim Nazareth, 15054-000 São José do Rio Preto, SP, Brazil \\ Phone: +55 $1732212260,+551732212250$, Fax +55 1732212299 \\ E-mail: vidianyqueiroz@yahoo.com.br \\ ${ }^{2}$ Engineering and Food Technology Department - São Paulo State University (UNESP) \\ Cristóvão Colombo Street, 2265, Jardim Nazareth, 15054-000 São José do Rio Preto, SP, Brazil \\ Phone: +55 173221 2260, +55 173221 2250; Fax: +55 1732212299 \\ E-mail: crispin@ibilce.unesp.br
}

(Submitted: June 3, 2015; Revised: January 12, 2016; Accepted: February 17, 2016)

\begin{abstract}
Two experiments were carried out using loofa sponge and sugarcane bagasse as immobilization support. First a $2^{(5-2)}$ design of experiments was realized with the following independent variables: sucrose concentration; $\mathrm{pH}$; incubation time and agitation. Based on the best results observed in this experiment, the capacity for reuse of the supports in subsequent fermentations was evaluated for 12 recycle days. Loofa sponge support was the best immobilization support and in the $2^{(5-2)}$ experiment, it showed $2.58 \mathrm{~g} . \mathrm{L}^{-1}$ of immobilized cells and 19.13 g.L $\mathrm{L}^{-1}$ of exopolysaccharide levan. Sugarcane bagasse showed the highest ethanol production (103.82 g. $\left.\mathrm{L}^{-1}\right)$. In the immobilization support recycling experiment, sugarcane bagasse was the most promising support since it showed cell viability up to the last fermentation cycle, confirmed by scanning electronic microscopy, also showing the largest values for immobilized biomass (3.23 g.L - $\left.^{-1}\right)$, levan (32.13 g.L $\left.{ }^{-1}\right)$, ethanol (148.18 g.L L $\left.^{-1}\right)$ and sucrose consumption ( $92.64 \%)$.

Keywords: bioethanol, microbial polysaccharide, immobilized cell, sequential batch.
\end{abstract}

\section{INTRODUCTION}

Bioethanol production arose as a means of solving the world energy crisis caused by the scarcity of fossil fuels (Bellido et al., 2011; Fan et al., 2013). On a worldwide scale, the ethanol production is concentrated in Brazil and the USA and uses edible raw materials, mainly sugarcane and corn, which is of concern in relation to food scarcity, due to the need to increase environmental exploration. Given this reality, intense research has been carried out throughout the world with a view to developing viable alternatives to increase the efficiency of ethanol production (Watanabe et al., 2012; Behera et al., 2012).
Zymomonas mobilis is a promising microorganism for ethanol and levan synthesis from sugar rich substrates, with a higher ethanol yield than presented by some commercial yeast strains. Levan production is interesting from the economic point of view, since it is a byproduct of ethanol synthesis when using sucrose rich substrates, which shows considerable potential for application in the food and pharmaceutical industries (Santos et al., 2014; Shih et al., 2010).

The use of immobilized cells is one of the different strategies studied to increase ethanol production that stands out, since it confers a series of advantages on the production system such as, for example, inoculum reuse

*To whom correspondence should be addressed 
during various fermentation cycles. Different techniques and supports for cell immobilization can be found in the literature, and the use of lignocellulosic supports such as loofa sponge and sugarcane bagasse has been widely cited (Chandel et al., 2009; Behera et al., 2012). These supports are used for immobilization by adsorption and are efficient due to presenting good stability to different chemical and physical treatments and having an extensive surface for cell adhesion.

Based on the need to develop technologies that make it possible to increase the ethanol and levan production using economically feasible and easily handled raw materials, the aim of this research was to evaluate the immobilization efficiency of Zymomonas mobilis CCT4494 on loofa sponge and sugarcane bagasse for ethanol and levan production, and also to evaluate the reuse of immobilized cell mass in sequential batch fermentations during various fermentation cycles.

\section{METHODS}

\section{Microorganism and culture media}

The microorganism used was Zymomonas mobilis CCT4494, obtained from the Tropical Culture Collection (CCT) of the "Andre Tosello" Research \& Technology Foundation - Campinas - SP - Brazil. The medium used for maintenance and pre-fermentation was Zymomonas mobilis broth (ZM broth) composed in $\mathrm{g} . \mathrm{L}^{-1}$ : yeast extract, 10.0; glucose, 20.0 and peptone, 10.0. The fermentation medium used was the basal medium, with the following composition in g.L $\mathrm{L}^{-1}$ : yeast extract, $5.0 ; \mathrm{KH}_{2} \mathrm{PO}_{4}, 1.0$; $\left(\mathrm{NH}_{4}\right)_{2} \mathrm{SO}_{4}, 1.0$ and $\mathrm{MgSO}_{4} .7 \mathrm{H}_{2} \mathrm{O}, 1.0$, and different sucrose concentrations.

\section{Fermentation conditions: Pre-fermentation and inoculum standardization}

Zymomonas mobilis CCT4494 was seeded into tubes containing ZM broth and incubated at $30{ }^{\circ} \mathrm{C}$ for 17 hours to reactivate the culture. After this period, the tube contents were poured into pre-fermentation flasks containing $50 \mathrm{~mL}$ of ZM broth and incubated under the same conditions. To carry out the assays, the contents of the pre-fermentation flasks were centrifuged at $3660 \mathrm{~g}$ for 15 minutes, the supernatant was discarded, and the cell pellet was suspended in $0.85 \%$ saline solution to obtain a concentrated cell suspension, which was standardized by spectrophotometry at $570 \mathrm{~nm}$ and inoculated in the immobilization supports (loofa sponge and sugarcane bagasse).

\section{Immobilization: adsorption on loofa sponge and sugarcane bagasse}

Immobilization was carried out by adsorption. The sugarcane bagasse and loofa sponge were previously washed with distilled water to remove impurities and then dried in an incubator at $55{ }^{\circ} \mathrm{C}$. The pieces of loofa sponge were fractionated to size $2 / 2 \mathrm{~cm}$, and then, the both immobilization supports was sterilized in autoclave at 121 ${ }^{\circ} \mathrm{C} / 15$ minutes. A quantity of $0.6 \mathrm{~g}$ of each support was added into the flasks containing pre-fermentation medium, which were inoculated with the cell suspension previously standardized and incubated in an orbital shaker at $30^{\circ} \mathrm{C}$ and $150 \mathrm{rpm}$ for 24 hours. After immobilization, the pieces of loofa sponge and sugarcane bagasse were washed in sterile distilled water to remove any microbiota not adhered in the supports and then, the immobilization supports were transferred under aseptic conditions to the Erlenmeyer flasks containing the fermentation medium and carbon source (sucrose).

\section{Experiment 1: Determination of the optimal conditions for ethanol and levan production}

A $2^{(5-2)}$ fractional factorial experimental design was used to define the best ethanol and levan production conditions using sugarcane bagasse and loofa sponge as the immobilization supports. The independent variables studied were: $\mathrm{X}_{1}$ : sucrose concentration in $\mathrm{g} . \mathrm{L}^{-1} ; \mathrm{X}_{2}$ : initial $\mathrm{pH} ; \mathrm{X}_{3}$ : temperature in ${ }^{\circ} \mathrm{C} ; \mathrm{X}_{4}$ : incubation time in $\mathrm{h}$; and $\mathrm{X}_{5}$ : medium agitation in rpm, resulting in 27 experiments with 2 repetitions, including a central point for each variable as shown in Table 1. At the end of the fermentations, samples were removed for determination of: final $\mathrm{pH}$; free biomass; immobilized biomass; ethanol and levan production and total sugars content.

Table 1. Independent variables studied in the $2^{(5-2)}$ experimental design.

\begin{tabular}{lccc}
\hline \multicolumn{1}{c}{ Variables } & $\mathbf{- 1}$ & $\mathbf{0}$ & $\mathbf{+ 1}$ \\
\hline $\mathrm{X}_{1}:$ Sucrose $\left(\mathrm{g} . \mathrm{L}^{-1}\right)$ & 150 & 250 & 350 \\
\hline $\mathrm{X}_{2}:$ Initial $\mathrm{pH}$ & 4.0 & 5.5 & 7.0 \\
\hline $\mathrm{X}_{3}:$ Time $(\mathrm{h})$ & 16 & 56 & 96 \\
\hline $\mathrm{X}_{4}:$ Temperature $\left({ }^{\circ} \mathrm{C}\right)$ & 30 & 35 & 40 \\
\hline $\mathrm{X}_{5}:$ Agitation $(\mathrm{rpm})$ & 0 & 100 & 200 \\
\hline
\end{tabular}


Experiment 2: Determination of the ethanol and levan production by sequential batch fermentation

Based on the best production conditions obtained in the $2^{(5-2)}$ experiments using response surface methodology, the supports were recycled during 12 cycles, each one for 24 hours of fermentation. At the end of each fermentation assay, the levan and ethanol production, free biomass, immobilized biomass and total sugars, were analyzed.

\section{Analytical methods}

The final $\mathrm{pH}$ value was determined directly in the fermented broth using a Digimed DM20 pHmeter. The free and immobilized biomasses were determined by spectrophotometry at $570 \mathrm{~nm}$. Immobilized biomass being evaluated after cell removal from the support by vigorous agitation in distilled water at $240 \mathrm{rpm}$ during 2 hours. Ethanol was determined by gas chromatography (Focus GC, TR-wax column $30 \times 0.053$, ID x $1 \mu \mathrm{m}$ ) and levan was evaluated with base on the technique described by Viikari (1984). The reducing sugars were evaluated using the copper-arsenate method described by Somogyi (1952) and Nelson (1944) and the total sugars by the phenol-sulfuric method described by Dubois et al. (1956). All the supports were examined by scanning electron microscopy according to the methodology proposed by Madi-Ravazzi (2012). The best parameters for the ethanol and levan production were determined by variance analysis (ANOVA) of the results and also by response surface methodology (RSM). The results obtained in the sequential batch fermentations during 12 days of support recycling were evaluated by variance analysis of and Tukey's test using the Minitab 14 software. The yield was determined according to the equation:

$$
\mathrm{Y}_{(\mathrm{P} / \mathrm{S})}=\left(\mathrm{P}_{\mathrm{f}}-\mathrm{P}_{0}\right) /\left(\mathrm{S}_{0}-\mathrm{S}_{\mathrm{f}}\right)
$$

where: $\mathrm{P}_{0}=$ initial product mass $\left(\mathrm{g} . \mathrm{L}^{-1}\right) ; \mathrm{P}_{\mathrm{f}}=$ final product mass (g.L $\left.\mathrm{L}^{-1}\right) ; \mathrm{S}_{0}=$ initial substrate concentration $\left(\mathrm{g} . \mathrm{L}^{-1}\right) ; \mathrm{S}_{\mathrm{f}}$ $=$ final substrate concentration $\left(\mathrm{g} \cdot \mathrm{L}^{-1}\right) ; \mathrm{Y}\left(\mathrm{P} / \mathrm{S}_{\mathrm{S}}\right)=$ coefficient of product yield in relation to the substrate consumed (g.g$\left.{ }^{1}\right)$. Substrate consumption was calculated by subtraction of the initial substrate concentration (sucrose) by final substrate concentration and the results were expressed in $\%$.

\section{RESULTS AND DISCUSSION}

\section{Experiment 1: Determination of the optimum conditions for ethanol and levan production by immobilized bacterium}

\section{Biomass immobilized on the support-immobilization efficiency and sucrose consumption}

As shown in Table 2, loofa sponge support presented the greatest value for immobilized biomass on the support (2.58 g. $\left.\mathrm{L}^{-1}\right)$, although no evaluated parameter affected statistically the cell growth on the support. On the other hand, sugarcane bagasse presented the greatest value for biomass $\left(0.82\right.$ g. $\left.\mathrm{L}^{-1}\right)$ using $35^{\circ} \mathrm{C}$, which was the only parameter that interfered statistically $(\mathrm{p}<0.05)$. A greater amount of free biomass was found in fermentation medium using loofa sponge support, with a maximum value of 3.87 g. $L^{-1}$ than with sugarcane bagasse support, which showed 2.67 g.. $\mathrm{L}^{-1}$ (Table 2).

The final $\mathrm{pH}$ value after fermentation showed similar behavior for the two supports, with a reduction to values between 3.51 and 4.98 and 3.44 and 3.89 for loofa sponge

Table 2. Fermentation parameters obtained by Z. mobilis CCT 4494 immobilized on loofa sponge and sugarcane bagasse support using a $2^{(5-2)}$ fractional factorial experimental design.

\begin{tabular}{|c|c|c|c|c|c|c|c|c|c|c|c|c|c|c|c|}
\hline $\mathbf{T}$ & $X_{1}$ & $X_{2}$ & $X_{3}$ & $X_{4}$ & $X_{5}$ & $\mathrm{IB}_{\mathrm{S}}$ & $\mathrm{IB}_{\mathrm{L}}$ & $\mathrm{FB}_{\mathrm{S}}$ & $\mathbf{F B}_{\mathrm{L}}$ & $\mathbf{L}_{\mathrm{s}}$ & $\mathbf{L}_{\mathbf{L}}$ & $\mathbf{E}_{\mathrm{s}}$ & $E_{L}$ & $\mathrm{pHf}_{\mathrm{s}}$ & $\mathrm{pHf}_{\mathrm{L}}$ \\
\hline 1 & 150 & 4.0 & 16 & 40 & 200 & 0.03 & 0.05 & 0.03 & 0.26 & 2.87 & 0.93 & 2.51 & 14.68 & 4.27 & 3.80 \\
\hline 2 & 350 & 4.0 & 16 & 30 & 0 & 0.35 & 0.35 & 0.11 & 1.27 & 6.60 & 8.73 & 5.84 & 33.77 & 4.25 & 3.78 \\
\hline 3 & 150 & 7.0 & 16 & 30 & 200 & 0.29 & 0.38 & 0.20 & 1.42 & 3.00 & 5.82 & 2.80 & 13.34 & 4.98 & 3.89 \\
\hline 4 & 350 & 7.0 & 16 & 40 & 0 & 0.19 & 0.41 & 0.01 & 1.68 & 19.1 & 6.62 & 42.63 & 103.82 & 4.39 & 3.56 \\
\hline 5 & 150 & 4.0 & 96 & 40 & 0 & 0.15 & 0.18 & 0.01 & 0.20 & 2.30 & 0.93 & 3.74 & 35.62 & 4.07 & 3.73 \\
\hline 6 & 350 & 4.0 & 96 & 30 & 200 & 0.34 & 0.37 & 0.01 & 1.66 & 11.4 & 10.0 & 0.68 & 0.84 & 3.61 & 3.44 \\
\hline 7 & 150 & 7.0 & 96 & 30 & 0 & 2.37 & 0.53 & 0.86 & 2.67 & 2.77 & 0.62 & 72.08 & 65.26 & 3.88 & 3.70 \\
\hline 8 & 350 & 7.0 & 96 & 40 & 200 & 0.64 & 0.28 & 3.87 & 1.15 & 8.97 & 0.75 & 2.70 & 88.43 & 4.29 & 3.79 \\
\hline 9 & 250 & 5.5 & 56 & 35 & 100 & 2.58 & 0.82 & 1.45 & 1.97 & 10.7 & 2.73 & 93.96 & 0.83 & 3.51 & 3.64 \\
\hline
\end{tabular}

(T): Tests; $\mathrm{X}^{1}$ : Sucrose (g.L $\left.\mathrm{L}^{-1}\right) ; \mathrm{X}^{2}$ : $\mathrm{pH} ; \mathrm{X}^{3}$ : Time (h); $\mathrm{X}^{4}$ : Temperature $\left({ }^{\circ} \mathrm{C}\right) ; \mathrm{X}^{5}$ : Agitation (rpm); S: Sugarcane bagasse; L: Loofa sponge;

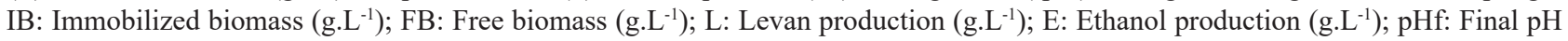
of the fermentation medium. 
and sugarcane bagasse, respectively (Table 2). This reduction could be due to the production of metabolites typical for the development of this microorganism (Swings; De Ley, 1977).

Table 3 shows the profiles of substrate consumption by $Z$. mobilis immobilized on the two supports. The loofa sponge support showed the greatest sucrose consumption (98.10\%), followed by the sugarcane bagasse with $91.97 \%$. In general, this microorganism showed high substrate consumption on both immobilization supports, although it appears that it was not used totally for the biomass, levan and ethanol synthesis, since the sum of the values obtained for these products was less than the total consumed. This behavior suggests the synthesis of other compounds, such as the non-precipitable levan cited by Viikari (1984) and sorbitol, or also acetic acid and lactate, among other compounds (Doelle et al., 1993).

Table 3. Sucrose consumption (SC) and final total sugars (TSf) using loofa sponge and sugarcane bagasse as immobilization supports.

\begin{tabular}{cccccccccccc}
\hline $\mathbf{T}$ & $\mathbf{X}_{\mathbf{1}}$ & $\mathbf{X}_{\mathbf{2}}$ & $\mathbf{X}_{\mathbf{3}}$ & $\mathbf{X}_{\mathbf{4}}$ & $\mathbf{X}_{\mathbf{5}}$ & $\mathbf{T S L}$ & $\mathbf{S C L}$ & $\mathbf{S C L S}^{\mathbf{a}}$ & $\mathbf{T S S}$ & $\mathbf{S C S}$ & $\mathbf{S C S}^{\mathbf{a}}$ \\
\hline $\mathbf{1}$ & 150 & 4.0 & 16 & 40 & 200 & 135.70 & 14.30 & 9.53 & 119.16 & 30.8 & 20.57 \\
$\mathbf{2}$ & 350 & 4.0 & 16 & 30 & 0 & 181.17 & 168.83 & 48.23 & 133.81 & 216.2 & 61.80 \\
$\mathbf{3}$ & 150 & 7.0 & 16 & 30 & 200 & 23.43 & 126.57 & 84.40 & 122.57 & 30.8 & 20.50 \\
$\mathbf{4}$ & 350 & 7.0 & 16 & 40 & 0 & 158.65 & 191.35 & 54.67 & 108.13 & 241.9 & 69.10 \\
$\mathbf{5}$ & 150 & 4.0 & 96 & 40 & 0 & 117.51 & 32.49 & 21.70 & 56.25 & 93.8 & 62.50 \\
$\mathbf{6}$ & 350 & 4.0 & 96 & 30 & 200 & 151.65 & 198.35 & 56.70 & 173.18 & 176.8 & 50.50 \\
$\mathbf{7}$ & 150 & 7.0 & 96 & 30 & 0 & 2.83 & 147.17 & 98.10 & 12.07 & 137.9 & 91.97 \\
$\mathbf{8}$ & 350 & 7.0 & 96 & 40 & 200 & 166.47 & 183.53 & 52.43 & 33.68 & 316.3 & 90.40 \\
$\mathbf{9}$ & 250 & 5.5 & 56 & 35 & 100 & 34.52 & 215.48 & 86.20 & 23.34 & 226.6 & 90.67 \\
\hline
\end{tabular}

(T): Tests; $\mathrm{X}^{1}$ : Sucrose (g.L $\left.\mathrm{L}^{-1}\right) ; \mathrm{X} 2 \mathrm{pH} ; \mathrm{X}^{3}$ : Time (h); $\mathrm{X}^{4}$ : Temperature $\left({ }^{\circ} \mathrm{C}\right) ; \mathrm{X}^{5}$ Agitation (rpm); TSL: Final total sugar for loofa sponge (g.L $\left.\mathrm{L}^{-1}\right)$; SCL and SCL ${ }^{\mathrm{a}}$ : Loofa sponge substrate consume (g.L $\left.\mathrm{L}^{-1}\right)$ and (\%); TSS: Final total sugar for sugarcane bagasse $\left(\mathrm{g} . \mathrm{L}^{-1}\right)$; SCS and $\mathrm{SCS}^{\mathrm{a}}$ : Sugarcane bagasse substrate consume $\left(\mathrm{g} \cdot \mathrm{L}^{-1}\right)$ and $(\%)$.

\section{Levan production}

Loofa sponge gave the highest values for levan production (2.3-19.1 g.L. $\left.\mathrm{L}^{-1}\right)$, followed by the sugarcane bagasse (0.62-10.0 g. $\left.\mathrm{L}^{-1}\right)$, according to Table 2 . It should be pointed out that the cell concentration on the support did not influence the levan synthesis by the supports evaluated, as described in Table 2. This support presented the highest values for levan yield, with $0.21 \mathrm{~g}^{-\mathrm{g}^{-1}}$ and 0.1 g. $\mathrm{g}^{-1}$ in experiments 1 and 4 , respectively (Table 2). In these experiments, the variables that interfered statistically were the initial $\mathrm{pH}$ value, fermentation time and temperature ( $\mathrm{p}$ $<0.05$ ), as highlighted in Figure 1A.

On the other hand, the sugarcane bagasse support showed a maximum levan yield of $0.04 \mathrm{~g}^{\mathrm{g}} \mathrm{g}^{-1}$ (experiment 1) and only agitation and fermentation time showed an influence on the levan synthesis increase (Table 2, Figure 1B).

The greater production by Z. mobilis immobilized on sugarcane bagasse at acid $\mathrm{pH}$ values, as observed in the present study, could be due to this $\mathrm{pH}$ value being close to the optimum value for levansucrase enzyme synthesis $(\mathrm{pH}$ 5.0), which is the enzyme responsible by levan formation. In addition, the synthesis of other oligosaccharides is stimulated at $\mathrm{pH}$ values above 5.0 (Yanase et al., 1992; Ananthalakshmy and Gunasekaran, 1999).

In relation to substrate consumption, this was not proportional to levan production for either support evaluated, indicating that the substrate could have been used principally for another metabolite production, such as sorbitol, not determined in this study.

There is controversy in the literature concerning the optimum parameters for this polymer synthesis, with a range of temperatures between 25 and $37{ }^{\circ} \mathrm{C}$ and $\mathrm{pH}$ values between 3.5 and 7.5. Other aspects that stand out in the literature for an increase in levan synthesis are the influences of parameters such as medium agitation and concentrations of yeast extract, nitrogen and mineral salts such as potassium chloride and sodium chloride (Bekers et al., 1999; Jerez, 1993).

Although not a statistically significant parameter, a relationship was shown between the highest sucrose concentration (350 g. $\mathrm{L}^{-1}$ ) and an increase in levan production on both supports, as shown in Table 2 .

Sprenger (1996) also cited that levan synthesis by Zymomonas mobilis occurred when the microorganism grew in culture media with high sucrose concentration. On the other hand, Yoshida et al. (1990) used 150 g.L. ${ }^{-1}$ of sucrose and obtained levan production of 35 g.L. $\mathrm{L}^{-1}$ using Z. mobilis (IN-17-10) and 3.1 g.L $\mathrm{L}^{-1}$ with Z. mobilis (IFO13757), both in $72 \mathrm{~h}$.

Contrary to that verified in this study using loofa sponge, Muro et al. (2000) evaluated levan production by Z. mobilis at different temperatures, and observed that levan synthesis was potentiated at temperatures below $30{ }^{\circ} \mathrm{C}$ during 5 days. They observed the greatest biopolymer production with the smallest values for biomass at $7{ }^{\circ} \mathrm{C}$.

Another important factor for levan synthesis by sugarcane bagasse support was the initial $\mathrm{pH}$ value of the fermentation medium, which gave the highest production 
when adjusted to 4 . This $\mathrm{pH}$ value was close to the optimum range cited in the literature for levan production, which was from 4.5 to 6 (Yokoya; Jerez, 1996; Swings; De Ley, 1977).

However, Ananthalakshmy and Gunasekaran (1999) evaluated levan production with the $\mathrm{pH}$ value adjusted to between 4.5 and 7 , and obtained the greatest levan production (14.5 g.. $\left.\mathrm{L}^{-1}\right)$ in a fermentation medium with an initial $\mathrm{pH}$ value of 5 . There was lower production at $\mathrm{pH} 7$ and no biopolymer production at $\mathrm{pH} 4$, possibly due to the low rate of cell growth observed at this $\mathrm{pH}$ value.

\section{Ethanol production}

The highest ethanol yields $\left(0.49{\mathrm{~g} . \mathrm{g}^{-1}}^{-1}\right)$ were obtained using loofa sponge as support, in experiment 7 using 150 g. $\mathrm{L}^{-1}$ sucrose and without agitation (Figure 1C; Table 2), all with significant statistical interference $(\mathrm{p}<0.05)$. On the other hand, the highest ethanol production (93.96 g.L $\mathrm{L}^{-1}$ ) was obtained in experiment 9, as shown in Table 2.
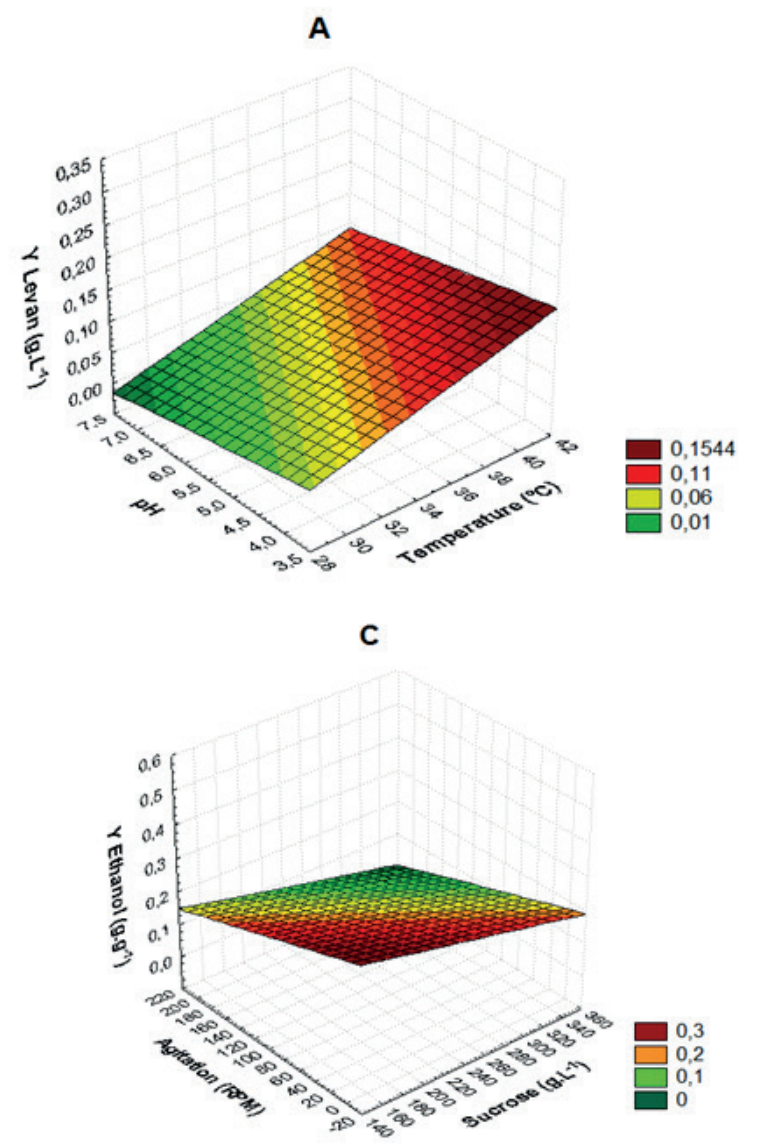

Sugarcane bagasse presented maximum yields of 0.42 and $0.28 \mathrm{~g} . \mathrm{g}^{-1}$ in experiments 4 and 8 , respectively (Table 2). The sucrose concentration, $\mathrm{pH}$ value adjusted to 7 and temperature were the variables that interfered to increase the production $(\mathrm{p}<0.05)$, as shown in Table 2 and Figure 1D. In relation to ethanol production, the highest values were obtained in experiments 4 (103.82 g.L. $\left.\mathrm{L}^{-1}\right)$ and 8 (88.43 g. $\left.\mathrm{L}^{-1}\right)$, according to Table 2 .

There is controversy in the literature in relation to the optimum conditions for ethanol production by Z. mobilis in immobilized systems. The most cited parameters are the initial $\mathrm{pH}$ of the fermentation medium, which should be between 4.5 and 7.5 ; temperatures between 25 and $37^{\circ} \mathrm{C}$ and sugar concentrations between 150 and 250 g.L L $^{-1}$ (Cazzeta et al., 2007; Bandaru et al., 2006). These parameters were evaluated for both immobilization supports (Table 1).

As mentioned by Bandaru et al. (2006), the most important physical parameters for ethanol synthesis are the temperature and initial $\mathrm{pH}$ value. This behavior was observed in the present study for sugarcane bagasse (Figure $1 \mathrm{D}$ and Table 2).

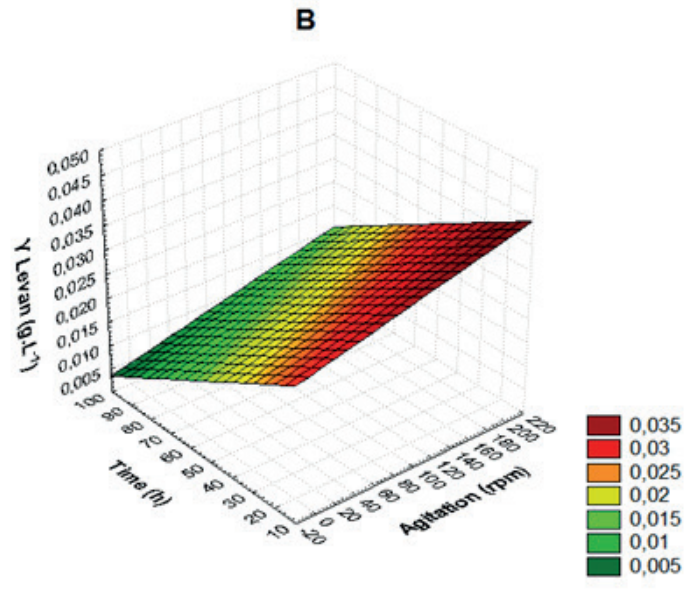

D

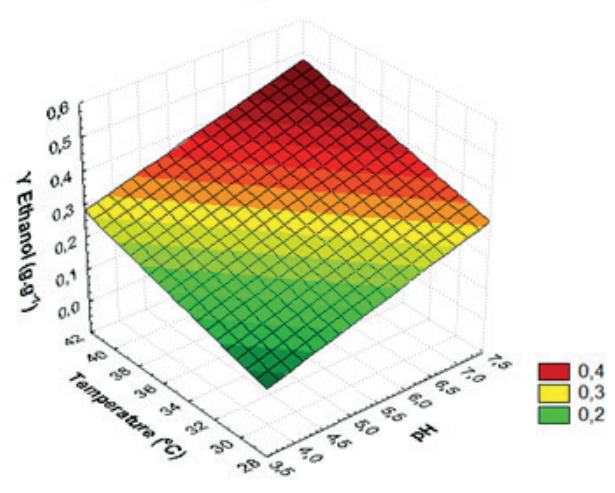

Figure 1. Response surfaces for levan yields (g.L $\left.\mathrm{L}^{-1}\right)$ using loofa sponge $(Y L=-0,1087+0,0076 * x-0,0158 * y)(\mathrm{A})$ and sugarcane bagasse $\left(Y L=0,0318+4,9167 E-5 * x-0,000 *^{*} y\right)(\mathrm{B})$ around the optimum values for $\mathrm{pH}$, temperature $\left({ }^{\circ} \mathrm{C}\right)$, time (h) and agitation (rpm) and response surfaces for the ethanol yields $\left(\mathrm{g} . \mathrm{L}^{-1}\right)$ using loofa sponge $(Y E=0,42-0,0007 * x$ $0,0008 * y)(\mathrm{C})$ and sugarcane bagasse $(Y E=-0,4137+0,0124 * x+0,0497 * y)$ (D) around the optimum values for agitation (rpm), sucrose $\left(\mathrm{g} \cdot \mathrm{L}^{-1}\right)$ temperature $\left({ }^{\circ} \mathrm{C}\right)$ and $\mathrm{pH}$. 
In relation to the influence of the initial $\mathrm{pH}$ of the fermentation medium, it was observed that initial $\mathrm{pH}$ values of 5.5 and 7 were the most efficient for both supports evaluated (Table 2). This behavior was also observed by Maiti et al. (2011) and Bandaru et al. (2006). Similar results were also observed by Vaheed et al. (2011), who obtained maximum ethanol yield by Z. mobilis when this bacterium was used free in the culture medium with initial $\mathrm{pH}$ adjusted to 5.2 .

The sucrose concentration used showed a negative statistically significant influence $(\mathrm{p}<0.05)$ on the greatest ethanol yield for both supports (Table 2). This behavior was not observed by Kannan et al. (1998) and Maiti et al. (2011). They cited 150 g.L. $\mathrm{L}^{-1}$ sucrose as the best sucrose concentration for ethanol biosynthesis.

In relation to the temperature, Sreekumar et al. (1999) and Cazzeta et al. (2007) cited a reduction in ethanol biosynthesis at temperatures above $40^{\circ} \mathrm{C}$, but this effect was not observed in the present study for sugarcane bagasse.

Bandaru et al. (2006), using sago starch as substrate, obtained an ethanol production of 55.3 g.L${ }^{1}$ by co-immobilization of Zymomonas mobilis and amyloglucosidase. These results were similar to those observed for loofa sponge and sugarcane bagasse supports, which were 93.96 and 103.82 g.L $^{-1}$, respectively, using the same microorganism (Table 2).

Similar to that observed with loofa sponge, Mathew et al. (2013) obtained greater ethanol production (169.26 g. $\left.\mathrm{kg}^{-1}\right)$ at a temperature of $30^{\circ} \mathrm{C}$ using rapeseed straw as the carbon source and the yeast Saccharomyces cerevisiae immobilized on alginate.

Das et al. (2013) evaluated the ethanol production from rice straw as a substrate for solid state fermentation, using a mixed culture of Zymomonas mobilis and Saccharomyces cerevisiae immobilized on sodium alginate and obtained $40.1 \mathrm{~g} . \mathrm{L}^{-1}$. This result was lower than those observed in the present study for both supports as shown in Table 2.

Sugarcane bagasse was the support giving the greatest ethanol production $\left(0.83-103.82\right.$ g.L.- $\left.\mathrm{L}^{-1}\right)$ followed by loofa sponge $\left(0.68-93.96\right.$ g.L $\left.\mathrm{L}^{-1}\right)$. In the same way as observed for levan production, cell concentration on the support did not influence the ethanol synthesis using the sugarcane support, as shown in Table 2. This occurred because the cell growth of $Z$. mobilis is independent of ethanol synthesis and, due to this peculiarity, this organism is considered an excellent ethanol producer (Kalneinieks, 2006). Opposite behavior was observed for loofa sponge, where the highest ethanol production was obtained in experiments with high immobilized biomass (Table 2).

\section{Experiment 2: Determination of ethanol and levan production by sequential batch fermentation}

Based on the best production conditions obtained in the $2^{(5-2)}$ experiments using response surface methodology, the recycling of supports was carried out for 12 days of fermentation. Optimum conditions for levan and ethanol production obtained for loofa sponge and sugarcane bagasse supports were: sucrose $350\left(\right.$ g.L.- $\left.{ }^{-1}\right), \mathrm{pH} 7$ and 4 , temperature $\left({ }^{\circ} \mathrm{C}\right)$ of 40 and $30^{\circ} \mathrm{C}$ and without agitation for loofa sponge and sugarcane bagasse, respectively.

\section{Free and immobilized biomass during the support reuse cycles}

Loofa sponge was efficient in Z. mobilis immobilization and showed a biomass of $0.06 \mathrm{~g} . \mathrm{L}^{-1}$ in the first fermentation cycle, with an increase in the fifth cycle to 0.45 g.L. ${ }^{-1}$, although the biomass immobilized on the support showed a reduction in growth in the last fermentation cycle to 0.13 g. $\mathrm{L}^{-1}$, as shown in Figure 2. Figure 3, obtained by scanning electron microscopy, shows the high level of microbial adhesion and also the morphological alterations presented by immobilized bacteria on the support after various fermentation cycles (Jamai et al., 2001).

Sugarcane bagasse support also was efficient for the immobilization, showing an initial growth of 1.51 g.L.- . An increase in biomass up to the fifth cycle was also shown, reaching 3.69 g. $\mathrm{L}^{-1}$, and a slight reduction in immobilized biomass to $3.23{\mathrm{~g} . \mathrm{L}^{-1}}^{-1}$ in the last fermentation cycle (Figure 2). Figure 3, obtained by scanning electron microscopy (SEM), shows the immobilization efficiency of $Z$. mobilis on the sugarcane bagasse support, where the high cell density can be seen on the support after various fermentation cycles.

In relation to support stability it can be seen that both remained stable and producing ethanol, levan and biomass throughout all the fermentation cycles, as can be seen in Table 4. Cell growth was observed during all the cycles by loofa sponge, with initial biomass of 0.41 g.L.-1 and maximum of $1.01 \mathrm{~g} . \mathrm{L}^{-1}$ in the third cycle. However, there was a reduction to 0.1 g. $\mathrm{L}^{-1}$ after the ninth cycle (Table 4). On the other hand, sugarcane bagasse support gave the highest values for free biomass in the culture medium, presenting an initial biomass of 1.24 g.L. $\mathrm{L}^{-1}$ with a maximum growth in the seventh cycle of 2.58 g. $\mathrm{L}^{-1}$ as shown in Table 4.

Based on the values found for free biomass with both supports studied, it was shown that, independent of the support used, there was a natural release of cells from the support into the culture medium, which grew and aided in product synthesis, leading to a mixed culture.

In relation to immobilization efficiency, the sugarcane support gave the highest values for immobilized biomass followed by the loofa sponge. It is important to point out that the immobilization supports remained viable throughout all the fermentation cycles, indicating that they could be used efficiently in semi-continuous and continuous fermentative processes. 


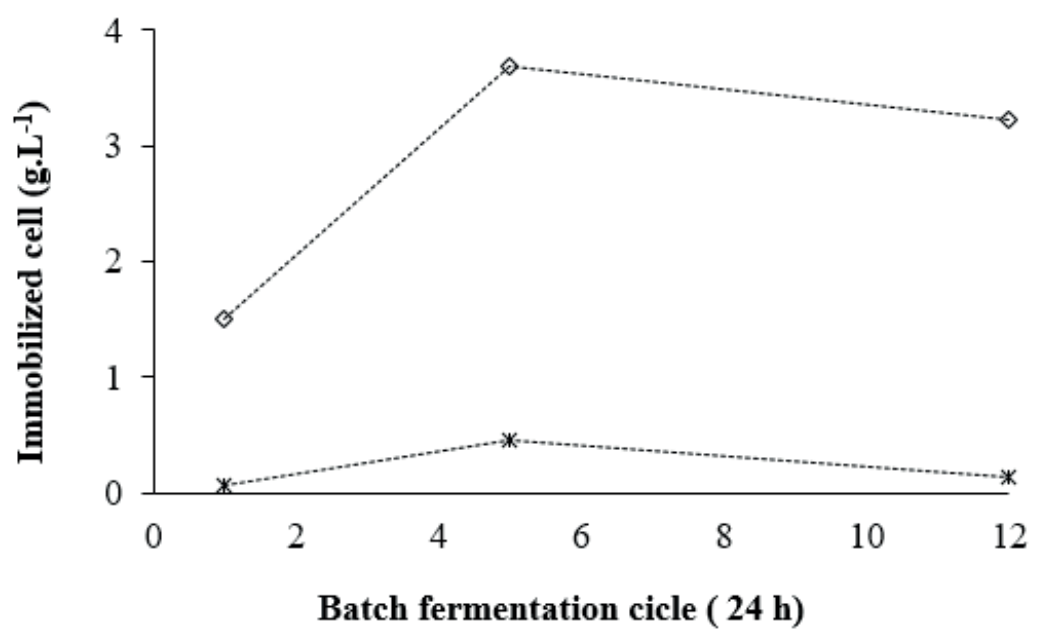

$\cdots-\cdots-\cdots$ Loofa sponge $\quad \cdots \leftrightarrow \cdots$ Sugarcane bagasse

Figure 2. Immobilized biomass on loofa sponge and sugarcane bagasse.

\section{Behavior of the final $\mathrm{pH}$ and substrate consumption during the support reuse cycles}

Final $\mathrm{pH}$ values observed using loofa sponge support presented variations during the reuse cycles, with reduced values in the first cycles (3.72-4.81) but only a slight reduction after the eighth cycle, remaining around 6.2 to 6.9 , indicating there could have been microorganism death on the support or its inhibition (Table 4). Values between 3.15 and 3.41 could be observed for sugarcane bagasse in all cycles with no oscillations until the last recycle (Table 4).

Medium acidification indicates that microorganisms remain metabolically active on the support, since acids are compounds synthesized by the microorganisms in addition to levan and ethanol, during substrate consumption.

In relation to substrate (sucrose) consumption, the maximum values of 92.64 and $90.18 \%$ were found in the fourth and fifth cycles using sugarcane bagasse. The loofa sponge support showed a maximum conversion of $84.04 \%$ in the first cycle and $79.66 \%$ in the second fermentation cycle, as shown in Table 4.

\section{Levan production during the support reuse cycles}

Loofa sponge support showed a maximum levan yield of $0.46 \mathrm{~g} . \mathrm{g}^{-1}$ in the fourth fermentation cycle, with significant statistical difference $(p<0.05)$ in relation to all the times evaluated. It was also observed that the production remained stable from the $7^{\text {th }}$ to $11^{\text {th }}$ fermentation cycles, with no significant statistical difference $(p<0.05)$ (Table 4 and Figure 4).
Throughout all the fermentation cycles using the loofa sponge support, the levan production presented values between 1.20 and 11.02 g. $\mathrm{L}^{-1}$ and a substrate consumption of 12.95 to $84.04 \%$, that is, the greatest consumption not was accompanied by a greater levan production (Table 4). In comparison with the batch cultivation (experiment 1), a lower production was found when used the semicontinuous system, indicating that the microorganism immobilized on this support did not adapt well to long fermentation periods.

The sugarcane bagasse support presented high levan production throughout all the recycles, with a maximum value of 32.13 g.L.-1 in the fourth reuse cycle (Table 4; Figure 4). After the eighth cycle the production remained practically constant with values between 15.79 and 12.39 g.L $\mathrm{L}^{-1}$.

In relation to substrate consumption, maximum values of 92.64 and $90.18 \%$ were found in the fourth and fifth cycles using sugarcane bagasse support. Loofa sponge support presented the lowest values, with maximum conversion of 84.04 and $79.66 \%$ in the first and second fermentation cycles, respectively, as shown in Table 4.

This support presented greater stability and production in a semi-continuous system than when using batch cultivation, as discussed in experiment 1 , indicating that sugarcane bagasse was a support adequate and efficient for use in semi-continuous fermentation systems.

These results are similar to those observed by Bekers et al. (2001), who obtained maximum levan production of 14.4 g.L. $\mathrm{L}^{-1}$, also using the bacterium Zymomonas mobilis immobilized on stainless steel spheres.

The maximum levan production observed using high sucrose concentrations has been cited by various 


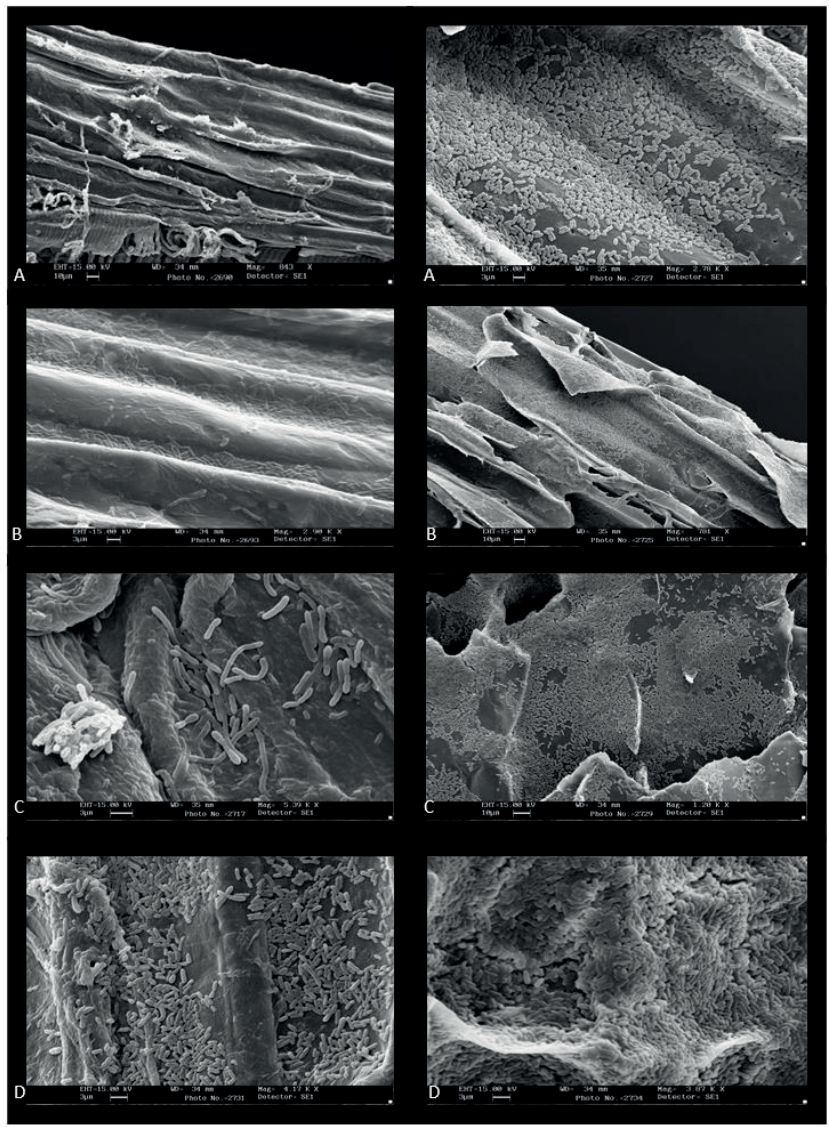

Figure 3. SEM of Z. mobilis CCT 4494 immobilized on loofa sponge (left) and sugarcane bagasse (right), respectively. (A: structure of support showing fissures); (B: Microbial cell adhered to the support structure soon after immobilization); (C: microbial cell adhered to the support, demonstrating good adhesion to the support and also the morphological alterations that occurred after various fermentation cycles); (D: high cell density adhered to the support after various fermentation cycles).
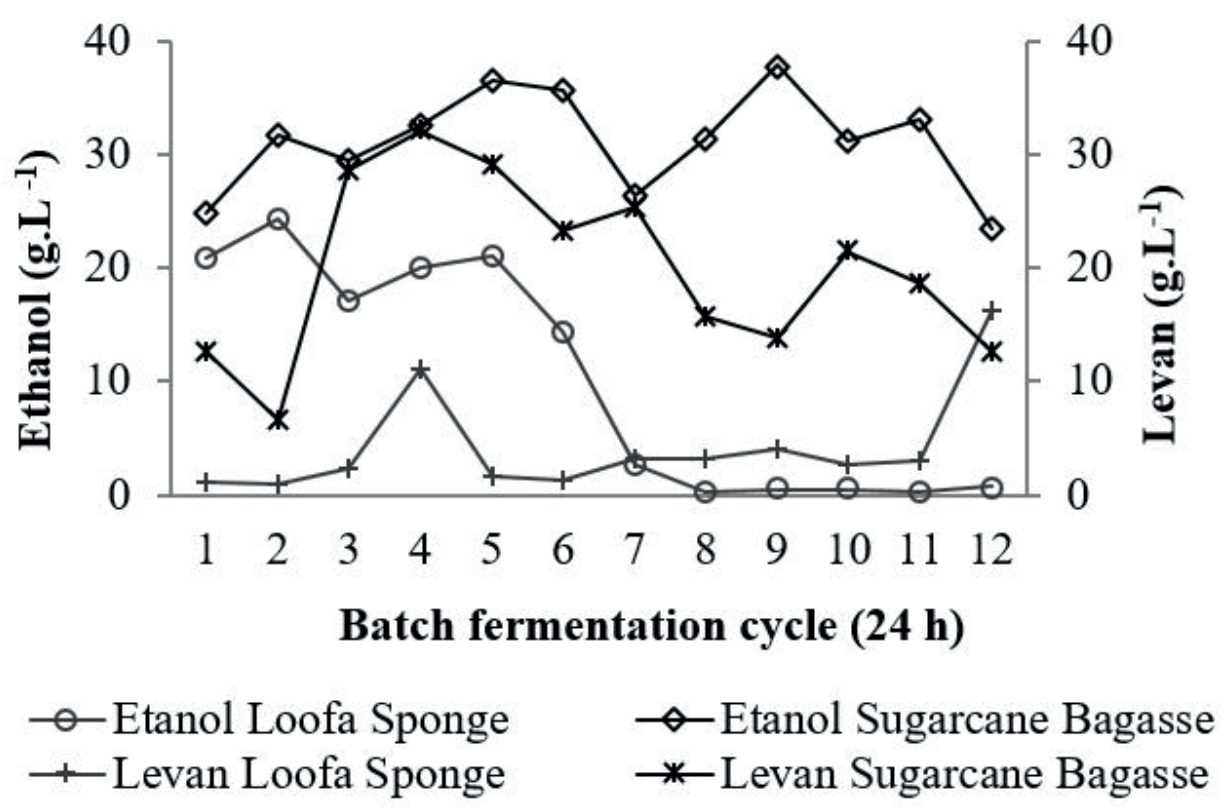

Figure 4. Levan and Ethanol production by Z. mobilis cells immobilized on loofa sponge and sugarcane bagasse during batch fermentation cycles. 
authors, who point out that, under these conditions, the microorganism redirects its metabolic pathway, and after hydrolyzing the sucrose into fructose and glucose units, initiates the transfructosylation of fructose units via the $\beta$ (2.6) bonds, forming the levan chain (Borsari et al., 2006; Sprenger, 1996; Yoshida et al.,1990).

Shih et al. (2007) obtained better results for levan using Bacillus subtilis nato immobilized on alginate spheres, and obtained maximum production in the third recycle (70.6 g. $\left.\mathrm{L}^{-1}\right)$, controlling the initial $\mathrm{pH}$ and medium supplementing with organic nitrogen during five reuse cycles, each for 72 $\mathrm{h}$. The authors perceived that the spheres remained stable during the five fermentation cycles.

It is important to point out that for both fermentation supports, the immobilized system remained viable up to the last fermentation cycle, with a high levan production, making it of interest for use in sequential batch fermentations, providing innumerous benefits such as lower operational costs when compared to the discontinuous system.

\section{Ethanol production during the support reuse cycles}

Greater yields were found for the loofa sponge support in the second $\left(0.31 \mathrm{~g} . \mathrm{g}^{-1}\right)$ and third $\left(0.34 \mathrm{~g} . \mathrm{g}^{-1}\right)$ cycles, with significant statistical difference $(p<0.05)$ between them, as shown in Table 4. There was a reduction after the fourth cycle to values next to zero, with no statistically significant difference between them, which could be due to the death of the microorganisms immobilized on the support (Table 4 and Figure 4). This behavior could be due to exposition of microorganisms to long periods of stress, such as, high temperatures and inhibitors like acetic acid, which are potentially inhibitors of the microbiota at concentrations above 3 g.L.-1 (Fan et al., 2013; Slininger et al., 2011; Jin et al., 2012).
Sugarcane bagasse presented higher ethanol yields in the eighth $\left(0.50 \mathrm{~g} . \mathrm{g}^{-1}\right)$ and third $\left(0.48 \mathrm{~g} . \mathrm{g}^{-1}\right)$ cycles, with no statistical difference between them $(\mathrm{p}<0.05)$. However, there was a fall in production after the eighth cycle and the values then remaining almost constant up to the $12^{\text {th }}$ recycle, without statistical interference, as shown in Table 4.

Similar to that observed for levan production, when compared with batch cultivation, it can be seen that the sugarcane bagasse support also presented high ethanol production during all the reuse cycles, indicating that it is also a promising support for sequential batch fermentation systems, as shown in Table 4 and Figure 4.

Singh et al. (2013) used sugarcane bagasse as immobilization support during 10 reuse cycles, and obtained a production of 15.4 to 15.1 g.L. $\mathrm{L}^{-1}$ from the first to the seventh fermentation cycles. The authors also observed a fall in production after the seventh cycle, indicating that the support was only efficient up to the seventh cycle. These results were inferior to those obtained in the present study using the same immobilization support as can be seen in Table 4 and Figure 4.

Watanabe et al. (2012), using Saccharomyces cerevisiae immobilized on a mixed alginate and resin support for ethanol production from rice straw hydrolysates, obtained production of 29.6 at 37.9 g.L.- $\mathrm{L}^{-1}$ in the first and fifth cycles, respectively. The immobilization support remained viable up to the last recycle, as observed in the present study for the sugarcane bagasse (Table 4).

The maximum ethanol yield obtained in the present study, using sugarcane bagasse as immobilization support (Table 4), was greater than that obtained by Chandel et al. (2009) using Saccharomyces cerevisiae V3 immobilized on sugarcane bagasse, where they obtained a yield of 0.44 g. $\mathrm{g}^{-1}$ after eight reuse cycles.

Inferior results to those obtained in the present study were also obtained by Ercan et al. (2013), who evaluated

Table 4. Fermentation parameters obtained for Z. mobilis CCT 4494 immobilized on loofa sponge and sugarcane bagasse support during reuse fermentation cycles.

\begin{tabular}{|c|c|c|c|c|c|c|c|c|c|c|c|c|c|c|}
\hline FC & $\mathbf{L}_{\mathrm{s}}$ & $\mathbf{L}_{\mathbf{L}}$ & $\mathbf{Y L}_{\mathrm{s}}$ & $\mathbf{Y L}_{\mathbf{L}}$ & Es & $E_{L}$ & $\mathbf{Y E}_{\mathrm{s}}$ & $\mathbf{Y E}_{\mathrm{L}}$ & SCs & FBs & pHfs & $\mathrm{SC}_{\mathrm{L}}$ & $\mathbf{F B}_{\mathrm{L}}$ & $\mathrm{pHf}_{\mathrm{L}}$ \\
\hline 1 & $12.7^{\mathrm{a}}$ & $1.67^{\mathrm{a}, \mathrm{c}, \mathrm{e}}$ & 0.044 & 0.07 & $104.0^{\mathrm{a}}$ & $54.30^{\mathrm{a}}$ & 0.36 & 0.18 & 82.86 & 1.24 & 3.30 & 84.04 & 0.41 & 3.87 \\
\hline 2 & $6.5^{\mathrm{a}, \mathrm{c}}$ & $1.08^{\mathrm{a}}$ & 0.023 & 0.05 & $108.6^{\mathrm{a}}$ & $86.56^{\mathrm{b}}$ & 0.38 & 0.31 & 81.14 & 1.53 & 3.20 & 79.66 & 0.31 & 3.77 \\
\hline 3 & $31.8^{\mathrm{b}}$ & $2.04^{\mathrm{a}, \mathrm{c}, \mathrm{d}, \mathrm{e}}$ & 0.107 & 0.09 & $141.8^{\mathrm{a}}$ & $69.89^{a}$ & 0.48 & 0.34 & 85.31 & 1.30 & 3.24 & 59.15 & 1.01 & 3.72 \\
\hline 4 & $32.1^{\mathrm{b}}$ & $11.02^{\mathrm{f}}$ & 0.099 & 0.46 & $148.1^{\mathrm{a}}$ & $46.25^{\mathrm{a}}$ & 0.46 & 0.18 & 92.64 & 1.45 & 3.22 & 75.30 & 0.39 & 3.70 \\
\hline 5 & $29.1^{\mathrm{b}, \mathrm{d}}$ & $2.57^{\text {a,c,d,e }}$ & 0.092 & 0.11 & $142.1^{\mathrm{a}}$ & $1.08^{\mathrm{c}}$ & 0.45 & 0.00 & 90.13 & 1.88 & 3.18 & 61.74 & 0.18 & 3.76 \\
\hline 6 & $23.2^{\mathrm{b}, \mathrm{e}}$ & $1.25^{\mathrm{a}, \mathrm{c}}$ & 0.076 & 0.05 & $119.2^{\mathrm{a}}$ & $27.23^{\mathrm{c}}$ & 0.39 & 0.14 & 87.08 & 1.86 & 3.17 & 56.35 & 0.21 & 3.95 \\
\hline 7 & $25.3^{\mathrm{b}, \mathrm{f}}$ & $3.19^{\mathrm{d}}$ & 0.084 & 0.13 & $133.4^{\mathrm{a}}$ & $4.27^{\mathrm{c}}$ & 0.44 & 0.02 & 86.60 & 2.58 & 3.22 & 54.51 & 0.06 & 4.07 \\
\hline 8 & $15.7^{\text {a,c,e,f }}$ & $3.11^{\mathrm{d}}$ & 0.058 & 0.13 & $142.5^{\mathrm{a}}$ & $0.41^{\mathrm{c}}$ & 0.50 & 0.00 & 78.09 & 2.51 & 3.19 & 67.94 & 0.02 & 4.81 \\
\hline 9 & $11.8^{\mathrm{a}, \mathrm{c}}$ & $3.35^{\mathrm{d}}$ & 0.042 & 0.14 & $82.23^{b}$ & $0.65^{\mathrm{c}}$ & 0.29 & 0.00 & 80.53 & 2.22 & 3.41 & 64.81 & 0.23 & 5.23 \\
\hline 10 & $21.4^{\mathrm{a}, \mathrm{d}, \mathrm{e}, \mathrm{f}}$ & $2.64^{\mathrm{d}, \mathrm{a}, \mathrm{b}}$ & 0.075 & 0.11 & $61.3^{\mathrm{b}}$ & $0.68^{c}$ & 0.22 & 0.00 & 81.42 & 2.18 & 3.16 & 40.47 & 0.10 & 6.29 \\
\hline 11 & $14.0^{\mathrm{a}, \mathrm{c}, \mathrm{e}}$ & $3.04^{\mathrm{d}, \mathrm{e}}$ & 0.051 & 0.13 & $72.37^{b}$ & $0.90^{c}$ & 0.26 & 0.00 & 79.38 & 2.39 & 3.18 & 70.92 & 0.10 & 6.59 \\
\hline 12 & $12.3^{\mathrm{a}, \mathrm{c}, \mathrm{e}}$ & $1.2^{\mathrm{a}, \mathrm{b}}$ & 0.042 & 0.05 & $55.98^{\mathrm{b}}$ & $0.77^{\mathrm{c}}$ & 0.19 & 0.02 & 83.74 & 1.43 & 3.23 & 12.95 & 0.10 & 6.67 \\
\hline
\end{tabular}

a,b.... (column) - means followed by the same small letter did not differ according to the Tukey test $(\mathrm{p}<0.05)$. FC: Fermentation cycles (24 hours); S: Sugarcane bagasse; L: Loofa sponge; L: Levan production (g.L-1); YL: Levan yield (g.g g $^{-1}$ ); E: Ethanol production (g.L-1); YE: Ethanol yield $\left(\mathrm{g} . \mathrm{g}^{-1}\right)$; SC: Substrate consumption (\%); FB: Free biomass (g.L $\left.\mathrm{L}^{-1}\right)$; pHf: Final pH value of the fermentation medium. 
the ethanol production from leguminous carob using Saccharomyces cerevisiae immobilized on alginate, during 5 fermentation cycles, and obtained their maximum ethanol production of $41.63 \mathrm{~g} . \mathrm{L}^{-1}$ in the first cycle. As from the second cycle they found a slight fall in production, with values between 36.45 and 40.27 g. $\mathrm{L}^{-1}$.

Fan et al. (2013), using Pichia guilliermondii to produce ethanol from corncob, obtained a production between 51.2 - 49.7 g.L $\mathrm{L}^{-1}$ from the first to the third fermentation cycles.

The above results indicate that Zymomonas mobilis immobilized on loofa sponge and sugarcane bagasse supports is a viable alternative for ethanol production, especially in batch fermentation process with reuse cycles from immobilization support, being the sugarcane bagasse a more promising support, since loofa sponge presented viable microbiota only up to the fourth cycle.

\section{CONCLUSIONS}

From the experiments carried out using statistical design, loofa sponge was the best support for Zymomonas mobilis immobilization and also for levan production. Sugarcane bagasse was the best support for ethanol synthesis. However, the biomass immobilized on the supports did not influence in the ethanol and levan production nor was the substrate consumption proportional to production. In the immobilization support recycling experiment, the opposite behavior was shown, the sugarcane bagasse support being more promising since it showed cell viability up to the last fermentation cycle, producing greater amounts of immobilized biomass, levan and ethanol. The microorganism on the loofa sponge only remained viable up to the fourth reuse cycle, showing that it was not adequate for semi-continuous fermentations.

\section{NOMENCLATURE}

$\begin{array}{ll}\text { CCT } & \text { Tropical Culture Collection of the } \\ & \text { "Andre Tosello" Research \& Technology } \\ & \text { Foundation - Campinas - SP - Brazil. } \\ Y L & \text { Levan Yield } \\ Y E & \text { Ethanol Yield } \\ Z M & \text { Z. mobilis }\end{array}$

\section{REFERENCES}

Ananthalakshmy, V.K., Gunasekaran, P., Optimization of levan production by Zymomonas mobilis. Brazilian Achieves of Biology and Technology, 42, 3, 291-298 (1999).

Bandaru, V.V.R., Somalanka, S.R, Mendu, D.R., Medicherla, N.R., Chityala, A. Optimization of fermentation conditions for the production of ethanol from sago starch by co-immobilized amyloglucosidase and cells of Zymomonas mobilis using response surface methodology. Enzyme Microbiology and Technology, 38, 209-214 (2006).

Behera, S., Ray, R.C., Monhanty, R.C. Ethanol fermentation of sugarcane molasses by Zymomonas mobilis MTCC 92 immobilized in Luffa cylindrica L. sponge discs and Ca-alginate matrices. Brazilian Journal of Microbiology, 43, 1499-507 (2012).

Bekers, M., Laukevics, J., Upite, D., Kaminska, E., Linde R. Flame burned stainless steel wire spheres as carrier of Zymomonas mobilis cells and extracellular levansucrase. Acta Biotechnology, 19, 341-348 (1999).

Bekers, M., Laukevics, J., Karsakevich, A., Ventina, E., Kaminska, E., Upite, D., Vina, I., Linde R., Scherbaka, $\mathrm{R}$. Levan-ethanol biosynthesis using Zymomonas mobilis cells immobilized by attachment and entrapment. Process Biochemistry, 36, 979-989 (2001).

Bellido, C., Bolado, S., Coca, M., Lucas, S., GonzálezBenito, G., García-Cubero, M.T. Effect of inhibitors formed during wheat straw pretreatment on ethanol fermentation by Pichia stipitis. Bioresource Technology, 102, 10868-10874, (2011).

Borsari, R.R.J.; Celliogi, M.A.P.C.; Buzato, J.B.; Silva, R.S.S.F. Influence of carbon source and the fermentation process on levan production by Zymomonas mobilis analyzed by the surface response method. Ciência e Tecnologia de Alimentos, 26, 604-609 (2006).

Cazzeta, M.L., Celligoi, M.A.P.C., Buzato, J.B., Scarmino, I. S. Fermentation of molasses by Zymomonas mobilis: Effects of temperature and sugar concentration on ethanol production. Biresource Technology, 98, 28242828 (2007).

Chandel, A. K., Narasu, M. L., Chandrasekhar, G., Manikyam, A., Rao, L. V. Use of Saccharum spontaneum (wild sugarcane) as biomaterial for cell immobilization and modulated ethanol production by thermotolerant Saccharomyces cerevisiae VS3. Bioresource Technology, 100, 2404-2410 (2009).

Das, A., Paul, T., Jana, A., Halder, S.K., Ghosh, K., Maity, C., Mohapatra, P.K.D., Pati, B. R., Mondal, K.C. Bioconversion of rice straw to sugar using multizyme complex of fungal origin and subsequent production of bioethanol by mixed fermentation of Saccharomyces cerevisiae MTCC 173 and Zymomonas mobilis MTCC 2428. Industrial Crops and Products, 46, 217-225 (2013).

Doelle, H.W., Kirk, L., Crittenden, R., Toh, H., Doelle, M.B. Zymomonas mobilis: science and industrial application. Critical Review Biotechnology, 13, 57-98 (1993).

Dubois, M., Gilles, K.A., Hamilton, J.K. Colorimetric method for determination sugars and related substances. Analytical Chemistry, 28, 350-356 (1956). 
Ercan, Y., Irfan, T., Mustafa, K. Optimization of ethanol production from carob pod extract using immobilized Saccharomyces cerevisiae cells in a stirred tank bioreactor. Bioresource Technology, 135, 365-371 (2013).

Fan, C., Qi, K., Xia, X.X., Zhong, J.J. Efficient ethanol production from corncob residues by repeated fermentation of an adapted yeast. Bioresource Technology, 136, 309-315 (2013).

Jamai, L., Sendide, K., Ettayebi, K., Errachidi, F., Hamdouni-Alami, O., Tahri-Jouti, M. A., Mcdermott, T., Ettayebi, M. Physiological difference during ethanol fermentation between calcium alginate-immobilized Candida tropicalis and Saccharomyces cerevisiae. Fems Microbiology Letters, 204, 375-379 (2001).

Jerez, M.C.D. Estudo comparativo de diferentes métodos e condições de fermentação de melaço de cana-de-açúcar por Zymomonas mobilis.1993. 108 f. Dissertação (Doutorado em Ciência de Alimentos) - Universidade Estadual de Campinas, Campinas, 1993.

Jin, M., Gunawan, C., Uppugundla, N., Balan, V., Dale, B.E. A novel integrated biological process for cellulosic ethanol production featuring high ethanol productivity, enzyme recycling and yeast cells reuse. Energy and Environmental Science, 5, 7168-7175 (2012).

Kalnenieks, U. Physiology of Zymomonas mobilis: some unanswered questions. Advances in Microbial Physiology, 51, 73-117 (2006).

Kannan, T.R.; Sangiliyandi, G.; Gunasekaran, P. Improved ethanol production from sucrose by a mutant of Zymomonas mobilis lacking sucrases in immobilized cell fermentation. Enzime Microbiology and Technology, 22, 179-184 (1998).

Madi-Ravazzi, L. Microscopia eletrônica de varredura com ênfase à análise de amostras biológicas. Universidade Estadual Paulista - IBILCE - Departamento de Biologia (2012).

Maiti, B., Rathore A., Srivastava, S., Shekhawat, M., Srivastava, P. Optimization of process parameters for ethanol production from sugar cane molasses by Zymomonas mobilis using response surface methodology and genetic algorithm. Applied Microbiology and Biotechnology, 90, 385-395 (2011).

Mathew, A.K., Crook, M., Chaney, K., Humphries, A.C. Comparison of entrapment and biofilm mode of immobilization for bioethanol production from oilseed rape straw using Saccharomyces cerevisiae cells. Biomass and Bioenergy, 52, 1-7 (2013).

Muro, A.C., Rodriguez, E., Abate, C.M., Siñeriz, F. Levan production using mutant strains of Zymomonas mobilis in different culture conditions. Biotechnology Letters, 22, 1639-1642 (2000).
Nelson, N. A photometric adaptation of Somogy method for determination of glucose. Biochem.153, 375-380 (1944).

Santos, V.A.Q., Del Bianchi, V.L., Garcia-Cruz, C.H. Effect of initial $\mathrm{pH}$ in levan production by Zymomonas mobilis immobilized in sodium alginate. Acta Scientiarium Technology, 36, 349-354 (2014).

Shih, I.L.;Chen, L.D.; Wu, J.Y. Levan production using Bacillus subtilis natto cells immobilized on alginate. Carbohydrate Polymers, 82, 111-117 (2010).

Singh, L., Siddiqui, M.F., Ahmad, A., Rahim, M.H.A., Sakinah, M., Wahid, Z. A. Biohydrogen production from palm oil mill effluent using immobilized mixed culture. Journal of Industrial and Engineering Chemistry, 19, 659-664 (2013).

Slininger, P.J., Thompson, S.R., Weber, S., Liu, Z.L., Moon, J. Repression of xylose specific enzymes byethanol in Scheffersomyces (Pichia) stipites and utility of repitching xylose-grown populations toeliminate diauxic lag. Biotechnology Bioengineering, 108, 18011815 (2011).

Somogyi, M. Notes on sugar determination. Journal of. Biological Chemistry, 195, 19 (1952).

Sprenger, G.A. Carbohydrate metabolism in Zymomonas mobilis: a catabolic highway with some scenic routes. F. Microbiology Letters, 145, 301-307 (1996).

Sreekumar, O., Chand, N., Basappa, S.C. Optimization and interaction of media components in ethanol production using Zymomonas mobilis by response surface methodology. Journal of Bioscience and Bioengineering, 88, 334-338 (1999).

Swings, S., De Ley, J. The biology of Zymomonas. Bacteriology Review, 41, 1-46 (1977).

Vaheed, H., Shojaosadati, S.A., Galip, H. Evaluation and optimization of ethanol production from carob pod extract by Zymomonas mobilis using response surface methodology. Journal of Industrial Microbiology and Biotechnology, 38, 101-111 (2011).

Viikari, L. Formation of levan and sorbitol from sucrose. Applied Microbiology and Biotechnology, 19, 252-255 (1984).

Watanabe, I., Miyata, N., Ando, A., Shiroma, R., Tokuyasu, K., Nakamura, T. Ethanol production by repeatedbatch simultaneous saccharification and fermentation (SSF) of alkali-treated rice straw using immobilized Saccharomyces cerevisiae cells. Bioresource Technology, 123, 695-698 (2012).

Yanase, H., Iwata, M., Nakahigashi, R., Kita, K., Kato, N., Tonomura, K. Purification, crystallization and properties of the extracellular levansucrase from Zymomonas mobilis. Bioscience Biotechnology and Biochemistry, 56, 1335-1337 (1992). 
Yokoya, F., Jerez, M.C.D. Efeito da temperatura e pH na produção de etanol e levana durante a fermentação de sacarose por Zymomonas mobilis. Arquives of Biology and Tecnology, 39, 129-137 (1996).
Yoshida, Y.; Suzuki, R.; Yagi, Y. Production of levan by a Zymomonas sp. Journal of Fermentation and Bioengineering, 70, 269-271 (1990). 